\title{
Academic Performance, Communication, and Psychosocial Development of Prelingual Deaf Children with Cochlear Implants in Mainstream Schools
}

\author{
Ji Eun Choi ${ }^{1}$, Sung Hwa Hong ${ }^{2}$, and II Joon Moon ${ }^{3}$ \\ ${ }^{1}$ Department of Otorhinolaryngology-Head and Neck Surgery, Dankook University Hospital, Cheonan, Korea \\ ${ }^{2}$ Department of Otorhinolaryngology-Head and Neck Surgery, School of Medicine, Sungkyunkwan University, \\ Samsung Changwon Hospital, Changwon, Korea \\ ${ }^{3}$ Department of Otorhinolaryngology-Head and Neck Surgery, School of Medicine, Sungkyunkwan University, \\ Samsung Medical Center, Seoul, Korea
}

$\begin{array}{ll}\text { Received } & \text { August 28, 2019 } \\ \text { Revised } & \text { October 15, 2019 } \\ \text { Accepted } & \text { November 15, 2019 }\end{array}$

Address for correspondence

Il Joon Moon, MD, $\mathrm{PhD}$

Department of Otorhinolaryngology-

Head and Neck Surgery,

School of Medicine,

Sungkyunkwan University,

Samsung Medical Center,

81 Irwon-ro, Gangnam-gu,

Seoul 06351, Korea

Tel +82-2-3410-3579

Fax +82-2-3410-3879

E-mail moonij@skku.edu
Background and Objectives: To assess the academic performance, communication skills, and psychosocial development of prelingual deaf children with cochlear implants (Cls) attending mainstream schools, and to evaluate the impact of auditory speech perception on their classroom performance. Subjects and Methods: As participant, 67 children with $\mathrm{Cl}$ attending mainstream schools were included. A survey was conducted using a structured questionnaire on academic performance in the native language, second language, mathematics, social studies, science, art, communication skills, self-esteem, and social relations. Additionally, auditory and speech performances on the last follow-up were reviewed retrospectively. $\mathbf{R e}$ sults: Most implanted children attending mainstream school appeared to have positive selfesteem and confidence, and had little difficulty in conversing in a quiet classroom. Also, half of the implanted children (38/67) scored above average in general academic achievement. However, academic achievement in the second language (English), social studies, and science were usually poorer than general academic achievement. Furthermore, half of the implanted children had difficulty in understanding the class content $(30 / 67)$ or conversing with peers in a noisy classroom (32/67). These difficulties were significantly associated with poor speech perception. Conclusions: Improving the listening environment for implanted children attending mainstream schools is necessary.

J Audiol Otol 2020;24(2):61-70

KEY WORDS: Cochlear implant · Mainstreaming education · Academic performance Psychosocial aspects.

\section{Introduction}

Profound deafness in childhood affects the development of auditory speech perception, speech production, and language skills. Failure to develop adequate oral communication skills can have a significant negative effect on academic performance and psychosocial development in these children. A cochlear implant (CI) is an electronic prosthetic device that is surgically placed in the inner ear to provide useful sound

This is an Open Access article distributed under the terms of the Creative Commons Attribution Non-Commercial License (https://creativecommons.org/licenses/by-nc/4.0/) which permits unrestricted non-commercial use, distribution, and reproduction in any medium, provided the original work is properly cited. perception by electrically stimulating the auditory nerve. It has been proved to be an effective management device for children with bilaterally severe-to-profound sensorineural hearing loss receiving limited benefit from hearing aids (HAs). Many studies have demonstrated the benefits of CIs concerning speech perception, production, and language development due to the enhanced audition provided by CIs [1-5]. Thus, the academic performance and psychosocial development of children with CIs is expected to be better than their non-implanted peers.

Over the past two to three decades, there has been a significant trend towards placing students with special educational needs in mainstream schools rather than in segregated spe- 
cial schools and special classes [6]. Besides, the proportion of children with CIs in mainstream schools has been steadily increasing [7-9]. Thus, classroom performance and social integration are some of the major challenges faced by children with CIs in mainstream schools. However, only a few studies have addressed the academic performance and psychosocial development of these children in mainstream schools, and have reported mixed results. Some studies reported that children with CIs in mainstream schools had satisfactory academic achievement $[10,11]$, while others reported that their academic performance lagged behind their normal-hearing peers $[12,13]$. Information on the subject-specific academic performance of these children is also lacking [13,14]. As with academic performance, wide variability in psychosocial development has been reported. Some studies reported positive findings regarding the social well-being and social functioning of children with CIs in mainstream schools $[12,15,16]$ while others revealed ongoing difficulties in social participation with normal-hearing peers [17-19].

For successful social integration of children with CIs in inclusive educational settings, the overall classroom performance of children with CIs in mainstream schools, and the factors affecting this performance need to be determined. Thus, our study aimed to assess the academic performance, communication skills, and psychosocial development of prelingual deaf children with CIs attending mainstream schools, and to evaluate the impact of auditory speech perception on their classroom performance. Given the lack of evaluation tools, we used structured questionnaires to examine academic performance in several subjects, communication skills, self-esteem, and the social relations of implanted children. We also reviewed medical speech evaluation records retrospectively.

\section{Subjects and Methods}

\section{Participants}

A prospective cohort study of prelingual deaf children with CIs was performed from August to September 2015. All children underwent CI before the age of 5 years at Samsung Medical Center and had at least 5 years of experience with the CI. Of the 149 children, 72 agreed to participate in the in-person or telephone interview along with their parents. Of the 72 children, 67 children attending mainstream schools were enrolled. Participants included 30 boys and 37 girls with an age range of 6 to 17 years [mean \pm standard deviation $(\mathrm{SD})=10 \pm 3$ years] at the time of the study. Before implantation, CI candidates underwent auditory brainstem response and auditory steadystate response to predict their hearing thresholds. All the children had bilateral profound sensorineural hearing loss ( $>90$
dB) across the speech frequency range and showed limited benefit from HAs in best-aided conditions. Fifty-one children were implanted with the Nucleus device (Cochlear Corporation, Lane Cove, New South Wales, Australia), and 16 children were implanted with the Clarion device (Advance Bionics Corporation, Sylmar, CA, USA). First devices were implanted at an age ranging from 13 months to 4 years 10 months (mean \pm $\mathrm{SD}=31 \pm 13$ months). The duration of implant usage ranged from 5 to 13 years (mean $\pm \mathrm{SD}=8 \pm 2$ years).

\section{Ethics statement}

All the participants were recruited and assessed in the Hearing Laboratory at the Samsung Medical Center. Written informed consent for participation was taken from each participant. The Institutional Review Board of Samsung Medical Center (IRB No. 2015-08-126-007) approved this study. All the study protocols were performed following the relevant guidelines and regulations.

\section{Auditory and speech performance evaluation}

Auditory and speech performances on the last follow-up at the Samsung Medical Center, at least 3 years after the implantation, were reviewed retrospectively. Aided pure-tone thresholds were measured in the sound field using warble tones presented from a loudspeaker located one meter away from the children at 0 degrees azimuth by an experienced audiologist [20]. The auditory perception was evaluated by the categories of auditory performance (CAP) scores. CAP comprises 8 hierarchical divisions of auditory perceptive ability: 0 , the lowest level, describes no awareness of environmental sounds; and 7, the highest level, describes the use of a telephone with a familiar speaker. Speech perception in both auditory-only (AO) and audiovisual conditions was evaluated using consonant-vowel-consonant monosyllabic and bi-syllabic words. Stimuli were presented using a monitored live voice of an experienced speech therapist. The presentation level was approximately $70 \mathrm{~dB}$ SPL, as determined with a handheld sound level meter. Children were instructed to repeat each presented stimulus. Speech acquisition and production were assessed using the speech production scale (SPC) and the modification of Ling's 7 distinct stages [21,22] of the normal data of Korean phoneme development. The SPC assesses phonetic (articulation) and phonologic (meaningful speech) acquisition levels at each stage in young children with CI. The 'staircase' diagram of SPC is illustrated in in Supplementary Material 1 (in the online-only Data Supplement).

\section{Questionnaires}

A survey of academic performance, communication skills, 
and psychosocial development were conducted through inperson or telephone interviews. A structured questionnaire was designed for children and their parents. Background information about device strategies (unilateral, bilateral, and bimodal CI users) and usage, communication modes (oral or/ and sign language), and school type were evaluated. Five categories of school enrollment were recognized: ordinary classes in mainstream schools, special classes in mainstream schools, special schools, schools for the deaf, and vocational schools. Grade retention, defined as the need to repeat a year due to failing grades, was also assessed. Academic achievement was assessed using quartiles and included the survey of overall academic performance, language (Korean and English), mathematics, social studies, science, and artistic performance (art and music). Communication development was assessed using closed questions on various situations at school and at home. Lastly, self-esteem and social relations were assessed by inquiring about friends and future hopes. An English translation of the questionnaire is provided in Supplementary Material 2 (in the online-only Data Supplement).

\section{Statistical analysis}

Results were analyzed using SPSS 18.0 (SPSS Inc., Chicago, IL, USA). Clinical information (age, sex, side of first CI, age at first CI, and duration of first CI use) and the results of auditory and speech performance evaluations were compared between the three listening modes using the Kruskal-Wallis and the chi-square tests. In case of a significant difference between the three listening modes, a post-hoc analysis using the Mann-Whitney test or chi-square test was performed to evaluate the differences between two different listening modes (i.e., unilateral CI users vs. bimodal listeners, unilateral CI users vs. bilateral CI users, and bimodal listeners vs. bilateral CI users). Chi-square test or Fisher's exact test was used to compare the distribution of responses to items on academic achievement, communication skills, and psychosocial development according to the three listening modes. To evaluate the impact of auditory speech perception ability on classroom performance, a multivariate logistic model was used to compare the bi-syllabic word recognition scores (WRSs) in AO condition and classroom performance after adjusting for the current age, sex, and listening modes. The Bonferroni correction was applied to the $p$-value because of multiple testing. Adjusted $p$-values were calculated by multiplying the original $p$-values by the number of comparisons ( 3 for listening modes). A $p$-value or adjusted $p$-value of less than 0.05 was considered statistically significant.

\section{Results}

\section{Demographics}

Among 67 children with CIs, 17 children (25\%) wore only one CI (unilateral CI users), 29 children (43\%) were experienced bimodal listeners with a CI in one ear and an HA in the other $(\mathrm{HA}+\mathrm{CI})$, and 21 children $(31 \%)$ received two implants in sequential procedures (bilateral $\mathrm{CI}$ users, $\mathrm{CI}+\mathrm{CI}$ ) with the interval between the first and second implantations ranging from $1-8$ years (mean \pm SD interval $=3 \pm 2$ years). All the children reportedly wore their device(s) more than $70 \%$ of the day and used oral communication. Supplementary Table 1 (in the online-only Data Supplement) includes the clinical and device information of each implanted children. Table 1 presents the comparison of the clinical information between the three listening modes (unilateral CI user, bimodal listener, and bilateral CI user). No significant difference was found in age and first CI information (side of first CI, age at first CI, and duration of first CI use) between the three listening modes. However, the sex ratio was significantly different between the three listening modes ( $p=0.035)$.

Table 1 also presents the comparisons of the auditory and speech performances between the three listening modes. No significant difference was found in aided pure-tone thresholds of the first device between the three listening modes. Supplementary Table 2 (in the online-only Data Supplement) includes the individual aided pure-tone thresholds at 250, 500 $\mathrm{Hz}, 1,2$, and $4 \mathrm{kHz}$. Most children showed good performance in speech evaluation 3 years after the implantation. However, there were significant differences in CAP scores $(p=0.006)$, WRSs ( $p<0.05$ for monosyllabic and bi-syllabic), and SPSs ( $p=0.001$ for phonetic level and $p=0.002$ for phonologic level) between the three different modes. Overall, the bimodal listeners and bilateral CI users showed significantly superior auditory perception (CAP scores and WRSs) and superior speech production in post-hoc analysis than unilateral CI users (Table 1). There were no significant differences in auditory perception and speech production between bimodal listeners and bilateral CI users in the post-hoc analysis.

\section{Academic performance}

Of the total 67 implanted children, 61 and 6 children were enrolled in ordinary classes with normal-hearing peers and a special class in a mainstream school, respectively. Grade retentions were reportedly experienced by 12 children (18\%) one or more times. Table 2 shows participants' clinical information and speech performance. Eight of these children were unilateral CI users, 1 child was a bimodal listener, and 3 were bilateral CI users. Two children had Noonan syndrome, 1 child 
had congenital heart disease, and 1 child had enlarged vestibular aqueduct syndrome.

Fig. 1A shows the academic performance of the $67 \mathrm{im}-$ planted children attending mainstream schools in each subject.
When the academic achievement was assessed using quartiles, $28,10,17$, and 12 implanted children had general academic achievement in the $1-25 \%$ (top 25\%), 26-50\%, 51-75\%, and $76-100 \%$ (bottom $25 \%$ ) of their class, respectively. Ac-

Table 1. Demographics of unilateral $\mathrm{Cl}$ users, bimodal listeners, and bilateral $\mathrm{Cl}$ users

\begin{tabular}{|c|c|c|c|c|c|c|c|}
\hline \multirow{2}{*}{ Variable } & $\begin{array}{l}\text { Group } 1 \\
(n=17)\end{array}$ & $\begin{array}{c}\text { Group } 2 \\
(n=29)\end{array}$ & $\begin{array}{l}\text { Group } 3 \\
(n=21)\end{array}$ & \multirow{2}{*}{ p-values } & \multirow{2}{*}{$\begin{array}{l}p^{*} \text { for } \\
\text { group } \\
1 \text { vs. } 2\end{array}$} & \multirow{2}{*}{$\begin{array}{l}p^{*} \text { for } \\
\text { group } \\
1 \text { vs. } 3\end{array}$} & \multirow{2}{*}{$\begin{array}{l}p^{*} \text { for } \\
\text { group } \\
2 \text { vs. } 3\end{array}$} \\
\hline & $\begin{array}{l}\text { Unilateral } \\
\mathrm{Cl} \text { users }\end{array}$ & $\begin{array}{l}\text { Bimodal } \\
\text { listeners }\end{array}$ & $\begin{array}{l}\text { Bilateral } \\
\mathrm{Cl} \text { users }\end{array}$ & & & & \\
\hline Age (years) & $11 \pm 3$ & $10 \pm 3$ & $10 \pm 3$ & $0.118^{\S}$ & & & \\
\hline Sex (male:female) & $11: 6$ & $8: 21$ & $11: 10$ & $0.035^{\dagger \|}$ & $0.042^{\dagger \|}$ & $1.332^{\dagger}$ & $0.225^{\dagger}$ \\
\hline Side of first device (right:left) & $9: 8$ & $14: 15$ & $16: 5$ & $0.125^{\dagger}$ & & & \\
\hline First device (Nucleus:Clarion) & $10: 7$ & $23: 6$ & $18: 3$ & $0.134^{\dagger}$ & & & \\
\hline Age at first $\mathrm{Cl}$ (months) & $30 \pm 13$ & $31 \pm 11$ & $30 \pm 15$ & $0.669^{\S}$ & & & \\
\hline Duration of first Cl use (years) & $9 \pm 3$ & $8 \pm 2$ & $8 \pm 2$ & $0.057^{\S}$ & & & \\
\hline Aided PTA of the first $\mathrm{Cl}$ (W4FA, dB HL) & $27 \pm 6$ & $28 \pm 11$ & $25 \pm 4$ & $0.538^{\S}$ & & & \\
\hline CAP scores & $5.8 \pm 1.2$ & $6.6 \pm 0.7$ & $6.7 \pm 0.7$ & $0.006^{\S \|}$ & $0.018^{\phi \|}$ & $0.021^{\phi \|}$ & $2.424^{\dagger}$ \\
\hline \multicolumn{8}{|l|}{ Mono-syllabic WRSs (\%) } \\
\hline AV condition & $80 \pm 32$ & $96 \pm 19$ & $99 \pm 5$ & $<0.001^{\S \|}$ & $0.003^{\phi \|}$ & $<0.001^{\phi \|}$ & $0.951^{\phi}$ \\
\hline AO condition & $61 \pm 31$ & $86 \pm 19$ & $93 \pm 8$ & $<0.001^{\S \|}$ & $<0.001^{中 \|}$ & $<0.001^{\$ \|}$ & $0.231^{\phi}$ \\
\hline \multicolumn{8}{|l|}{ Bi-syllabic WRSs (\%) } \\
\hline AV condition & $85 \pm 32$ & $96 \pm 19$ & $99 \pm 5$ & $0.009^{\S \|}$ & $0.066^{\phi}$ & $0.027^{\dagger \|}$ & $0.951^{\phi}$ \\
\hline AO condition & $68 \pm 33$ & $89 \pm 19$ & $95 \pm 8$ & $<0.001^{\S \|}$ & $0.018^{\phi \|}$ & $<0.001^{\ddagger \|}$ & $0.165^{\dagger}$ \\
\hline \multicolumn{8}{|l|}{ Speech production scale } \\
\hline Phonetic level & $6.3 \pm 1.3$ & $7.3 \pm 0.9$ & $7.6 \pm 0.7$ & $0.001^{\S \|}$ & $0.012^{\phi \|}$ & $0.003^{\phi \|}$ & $0.882^{\phi}$ \\
\hline Phonologic level & $6.6 \pm 1.2$ & $7.4 \pm 0.9$ & $7.7 \pm 0.6$ & $0.002^{\S \|}$ & $0.045^{\phi \|}$ & $0.003^{\phi \|}$ & $0.345^{\dagger}$ \\
\hline
\end{tabular}

Continuous values were presented as mean \pm standard deviation. *Adjusted $p$-values were calculated by multiplying the original $p$-values by 3 pairs, ${ }^{\dagger}$ chi-squared test, ${ }^{\dagger}$ Mann-Whitney test, ${ }^{\S}$ Kruskal-Wallis test, " $p<0.05$. Cl: cochlear implant, PTA: pure-tone average, W4FA: weighted four-frequency average [W4FA $=(0.5 \mathrm{kHz}+2 \times 1 \mathrm{kHz}+2 \times 2 \mathrm{kHz}+4 \mathrm{kHz}) / 6$ ], CAP: categories of auditory performance, AV: audiovisual, AO: auditory-only, WRS: word recognition score

Table 2. Clinical information and speech performance of children who experienced grade retention

\begin{tabular}{|c|c|c|c|c|c|c|c|c|}
\hline \multirow[b]{2}{*}{ Subject } & \multirow[b]{2}{*}{ Sex } & \multirow[b]{2}{*}{$\begin{array}{c}\text { Current } \\
\text { age (year) }\end{array}$} & \multicolumn{3}{|c|}{ First Cochlear Implantation } & \multirow[b]{2}{*}{$\begin{array}{l}\text { Aided PTA } \\
\text { W4F } \\
(\mathrm{dB} \mathrm{HL})\end{array}$} & \multirow[b]{2}{*}{$\begin{array}{c}\text { Bi-syllabic } \\
\text { WRS in AO } \\
\text { condition (\%) }\end{array}$} & \multirow[b]{2}{*}{ Comments } \\
\hline & & & $\begin{array}{l}\text { Type of } \\
\text { device }\end{array}$ & $\begin{array}{c}\text { Age at } \\
\text { implantation } \\
\text { (month) }\end{array}$ & $\begin{array}{l}\text { Duration } \\
\text { of Cl use } \\
\text { (year) }\end{array}$ & & & \\
\hline $\mathrm{UCl} 5$ & M & 15 & $\mathrm{~N}$ & 50 & 12 & 28.3 & 60 & Congenital heart disease \\
\hline $\mathrm{UCl} 6$ & M & 14 & C & 36 & 11 & 35.0 & 0 & \\
\hline UCl11 & M & 10 & $\mathrm{~N}$ & 24 & 9 & 18.3 & 92 & \\
\hline UCl12 & $\mathrm{F}$ & 12 & C & 39 & 9 & 30.8 & 0 & \\
\hline UCl14 & $\mathrm{F}$ & 14 & $\mathrm{~N}$ & 47 & 10 & 36.7 & 36 & \\
\hline UCl15 & $\mathrm{F}$ & 12 & C & 35 & 10 & 23.3 & 80 & \\
\hline UCI16 & M & 11 & C & 23 & 10 & 25.0 & 76 & Revision $\mathrm{Cl}$ ( 3 years after $\mathrm{Cl}$ ) \\
\hline UCl17 & M & 7 & $\mathrm{~N}$ & 32 & 5 & 29.2 & 84 & \\
\hline $\mathrm{Cl}+\mathrm{HA} 12$ & $\mathrm{~F}$ & 9 & $\mathrm{~N}$ & 27 & 7 & 22.5 & 84 & Noonan syndrome \\
\hline $\mathrm{BCl} 2$ & $\mathrm{~F}$ & 17 & $\mathrm{~N}$ & 58 & 12 & 27.5 & 88 & \\
\hline $\mathrm{BCl} 4$ & $\mathrm{~F}$ & 9 & $\mathrm{~N}$ & 21 & 8 & 22.5 & 100 & EVAS \\
\hline $\mathrm{BCl} 18$ & M & 8 & C & 18 & 7 & 26.7 & 100 & Noonan syndrome \\
\hline
\end{tabular}

M: male, F: female, N: Nucleus, C: Clarion, Cl: cochlear implant, PTA: pure-tone average, W4F: weighted four-frequency average [W4F $=(0.5 \mathrm{kHz}+2 \times 1 \mathrm{kHz}+2 \times 2 \mathrm{kHz}+4 \mathrm{kHz}) / 6]$, EVAS: enlarged vestibular aqueduct syndrome, WRS: word recognition score, $\mathrm{AO}$ : auditory-only, $\mathrm{UCl}$ : unilateral $\mathrm{Cl}, \mathrm{HA}$ : hearing aid, $\mathrm{BCl}$ : bilateral $\mathrm{Cl}$ 

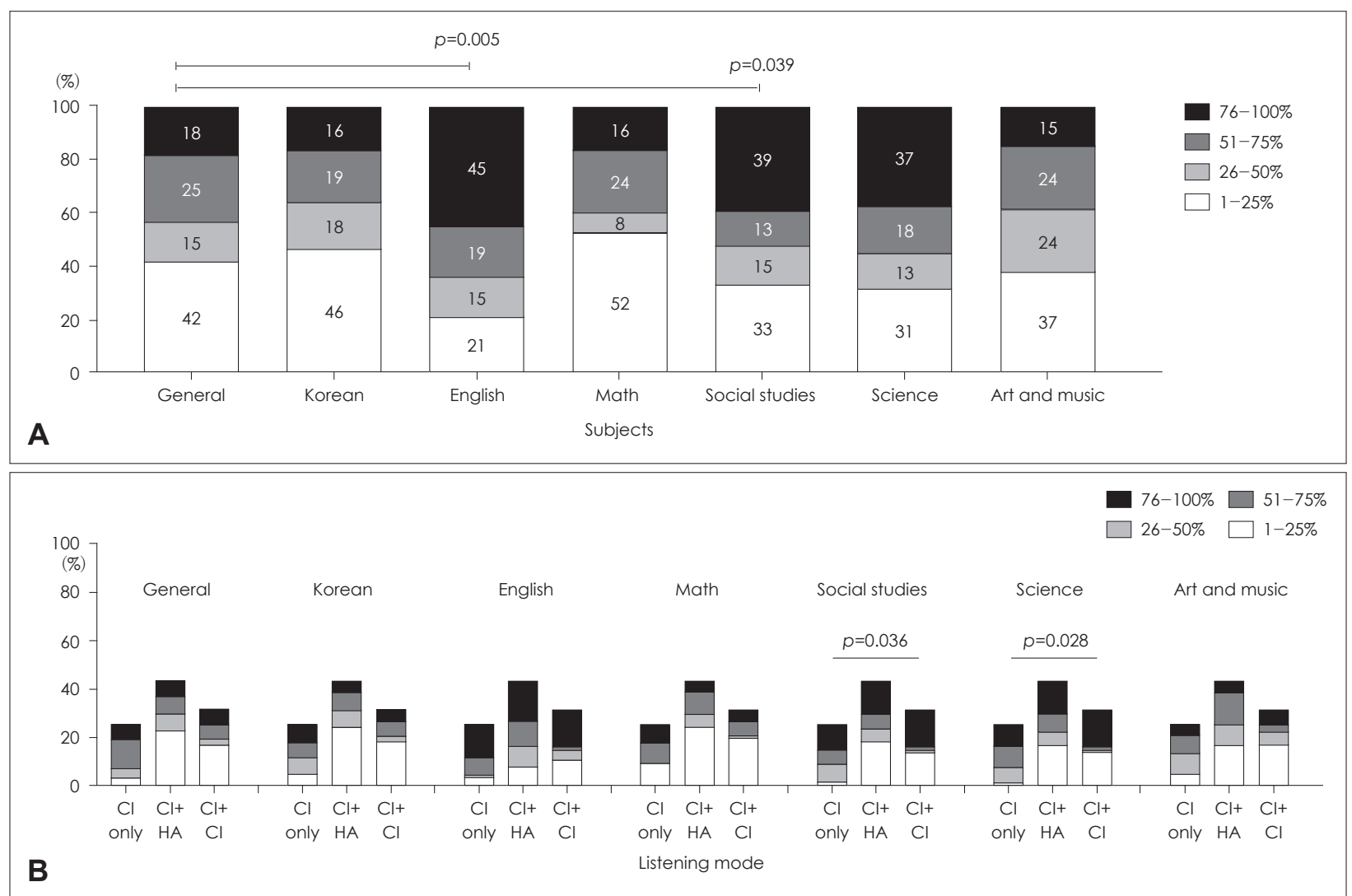

Fig. 1. Academic performance according to subject $(A)$ and listening mode (B). The academic achievement of each subject is presented as a proportion of four quartiles. The upper quartile (1-25\%) refers to the top $25 \%$ of students, and the lower quartile (76-100\%) the bottom $25 \%$. A $p$-value $(p)$ less than 0.05 was considered to indicate statistical significance. Cl: cochlear implant, HA: hearing aid.

ademic achievements in English ( $p=0.005$ in chi-square test) and social studies ( $p=0.039$ in chi-square test) were significantly lower than general academic achievement. Fig. 1B shows the academic performance in each subject according to the listening modes. Academic achievement in social studies ( $p=0.036$ in Fischer's exact test) and science ( $p=0.028$ in Fischer's exact test) differed significantly according to the listening modes. In post-hoc analysis with Fischer's exact test, unilateral CI users showed poorer academic achievement in social studies (adjusted $p=0.026$ ) and science (adjusted $p=0.014$ ) than bilateral CI users. These differences were insignificant between bimodal listeners and bilateral CI users.

\section{Communication skills and psychosocial development}

Table 3 shows communication skills at school and at home, and psychosocial development of the 67 implanted children attending mainstream schools. About half (55\%) of the children understood all or almost all of the teaching content (Q1 at school). In a quiet classroom, most implanted children (79\%) reported little or no difficulty during one-on-one conversations (Q2 at school). Also, most implanted children (88\%) experienced little or no stress conversing with an unfamiliar person at school (Q4 at school). However, half of the implanted children $(48 \%)$ reported some difficulty during individual conversations in a noisy classroom (Q3 at school). Difficulty in communicating during class (Q1 at school) or in a quiet classroom (Q2 at school) differed significantly depending on the listening mode. In post-hoc analysis with Fischer's exact test, bilateral CI users understood the class content better than bimodal listeners (adjusted $p=0.037$ ) and were more comfortable with individual conversations in a quiet classroom than unilateral CI users (adjusted $p=0.02$ ).

Implanted children generally experienced more difficulty communicating at school than at home. At home, 91\% and $76 \%$ of implanted children reported little or no difficulty communicating in a quiet and noisy background, respectively (Q1 and Q2 at home). However, only 34\% of the implanted children were able to understand all or almost all the words of their family while concentrating on other things (Q3 at home). No significant difference was found in communication skills at home between the three listening modes.

A survey of psychosocial development revealed that most implanted children $(96 \%)$ had a friend with normal hearing (Q1), and $96 \%$ of implanted children were unafraid of making 
Table 3. Communication skills and psychosocial development

\begin{tabular}{lcccc}
\hline Questionnaire & Total & $\begin{array}{c}\text { Unilateral } \\
\mathrm{Cl} \text { users }\end{array}$ & $\begin{array}{l}\text { Bimodal } \\
\text { listeners }\end{array}$ & $\begin{array}{c}\text { Bilateral } \\
\mathrm{Cl} \text { users }\end{array}$ \\
\hline
\end{tabular}

Communication at school

Q1. In the class,

Al I can understand all the teaching content.

A2 I can understand almost all the teaching content.

A3 I can understand about half of the teaching content.

A4 I can understand only $20-30 \%$ of the teaching content.

A5 I barely understand the teaching content.

Q2. During a one-on-one conversation with a friend in a quiet classroom,

A1 I have no difficulty having a conversation.

A2 I have a little difficulty having a conversation.

A3 I can understand about half of my friend's words.

A4 I can understand $20-30 \%$ of my friend's words.

A5 I struggle to have a conversation.

Q3. During a one-on-one conversation with a friend in a noisy classroom,

Al I have no difficulty having a conversation.

A2 I have a little difficulty having a conversation.

A3 I can understand about half of my friend's words.

A4 I can understand $20-30 \%$ of my friend's words.

A5 I struggle to have a conversation.

Q4. During conversation with an unfamiliar person,

Al I can converse without stress. 29

A2 I am slightly stressed during the conversation, but I can still talk. 30

A3 I try to avoid the conversation as much as possible.

A4 I absolutely avoid the conversation.

Communication at home

Q1. During conversation with family in a quiet background,

Al I have no difficulty having a conversation.

A2 I have a little difficulty having a conversation.

A3 I can understand about half of my family's words.

A4 I can understand $20-30 \%$ of my family's words.

A5 I struggle to have a conversation.

Q2. During conversation with family in a noisy background,

A1 I have no difficulty having a conversation.

A2 I have a little difficulty having a conversation.

A3 I can understand about half of my family's words.

A4 I can understand $20-30 \%$ of my family's words.

A5 I struggle to have a conversation.

\section{3}

24

25

4

1

37

16

11

3

0
$0.004^{* \dagger}$

$\begin{array}{rrr}2 & 2 & 9 \\ 5 & 12 & 7 \\ 6 & 14 & 5 \\ 4 & 0 & 0 \\ 0 & 0 & 0\end{array}$

$0.033^{+}$

14

6

0

1

0

$0.382^{\dagger}$

$0.968^{\dagger}$

$0.664^{\dagger}$

$0.786^{\dagger}$

$\begin{array}{rrrr}23 & 4 & 11 & 8 \\ 28 & 7 & 11 & 10 \\ 12 & 5 & 5 & 2 \\ 4 & 1 & 2 & 1 \\ 0 & 0 & 0 & 0\end{array}$

Q3. If my family suddenly speaks to me while I am concentrating on other things (e.g., watching TV, reading a book), $0.814^{\dagger}$

\begin{tabular}{|c|c|c|c|c|c|}
\hline Al I can understand all the words. & 4 & 0 & 1 & 3 & \\
\hline I can understand almost all the words. & 19 & 5 & 8 & 6 & \\
\hline Sometimes I ask what was said because I have missed words. & 32 & 8 & 16 & 8 & \\
\hline I usually ask what was said because I have missed words. & 9 & 3 & 3 & 3 & \\
\hline I miss words spoken by my family. & 3 & 1 & 1 & 1 & \\
\hline \multicolumn{6}{|l|}{ esteem and social relations } \\
\hline 1. My friends & & & & & $0.784^{\dagger}$ \\
\hline Al Mostly have normal hearing. & 64 & 17 & 27 & 20 & \\
\hline $\begin{array}{l}\text { Mostly have hearing loss and use hearing aids or } \\
\text { cochlear implants. }\end{array}$ & 0 & 0 & 0 & 0 & \\
\hline
\end{tabular}

66 J Audiol Otol 2020;24(2):61-70 
Table 3. Communication skills and psychosocial development (continued)

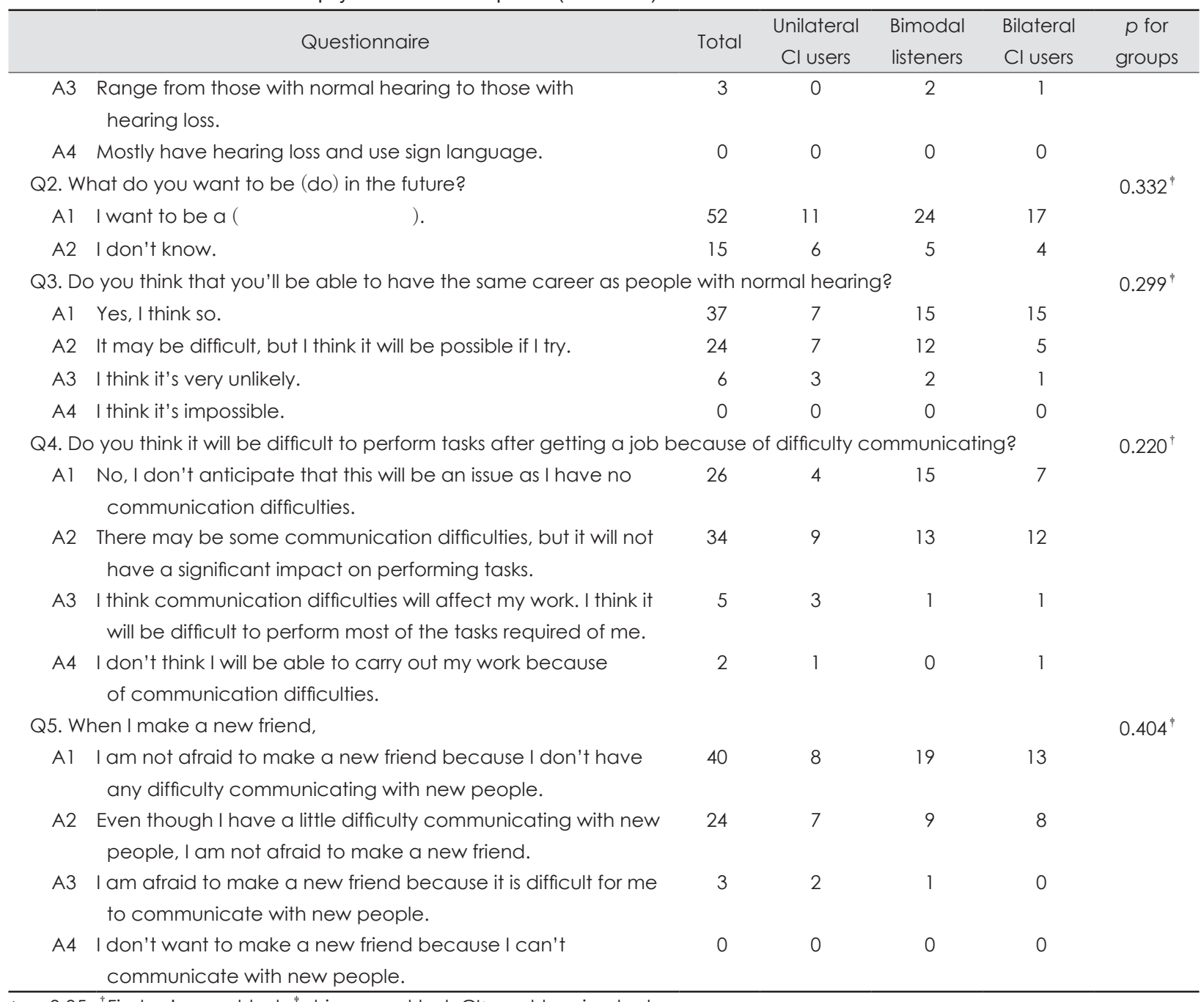

*p<0.05, ${ }^{\dagger}$ Fischer's exact test, ${ }^{\dagger}$ chi-squared test. $\mathrm{Cl}$ : cochlear implant

a new friend (Q5). When asked about their future careers, 78\% of the children wanted a job (Q2) in various fields regardless of their communication skills. Furthermore, $91 \%$ and $90 \%$ of the implanted children responded positively when asked about getting a job (Q3) and performing workplace tasks (Q4) in the future. No significant difference was seen in the responses to the psychosocial development survey between the three listening modes.

\section{The impact of auditory speech performance on classroom performance}

Bivariate logistic regression models were constructed to examine the relationship between bi-syllabic WRS in AO condition and classroom performance (Table 4). Classroom performance (academic achievement and communication at school) was divided into good and poor performance based on the questionnaire responses. Good performers were defined as children who scored above average (within the top 50\%) on the academic achievement questionnaires, or to the top 1 and 2 on the communication skills questionnaires. The remaining were defined as children with poor performance. A multivariate logistic regression model was constructed while adjusting for potential confounders (current age, sex, and listening modes). In the crude model, high scores on the bi-syllabic WRSs were significantly associated with a decrease in the odds of having poor academic performance in all subjects except art and music (all $p<0.05)$. However, academic achievement in art and music was not significantly associated with the bi-syllabic WRSs. In the adjusted model, the bi-syllabic identification scores were significantly associated with academic achievement in Korean, social studies, and science (all $p<0.05$ ). High scores on the bi-syllabic WRSs were also significantly associated with a decrease in the odds of having communication difficulties at school (all $p<0.05$ in the adjusted model). 
Table 4. Relationship among bi-syllabic word recognition and classroom performance

\begin{tabular}{|c|c|c|c|c|c|c|c|}
\hline \multirow{2}{*}{ Variables } & \multirow{2}{*}{$\begin{array}{l}\text { Good (ref) vs. poor } \\
\text { performers }\end{array}$} & \multicolumn{2}{|c|}{ Bi-syllabic WRS (\%) } & \multicolumn{2}{|c|}{ Crude model } & \multicolumn{2}{|c|}{ Adjusted model* } \\
\hline & & $\mathrm{N}$ & Mean \pm SD & OR & $95 \% \mathrm{Cl}$ & OR & $95 \% \mathrm{Cl}$ \\
\hline \multicolumn{8}{|c|}{ Academic achievement } \\
\hline \multirow[t]{2}{*}{ General } & $1-50 \%$ & 38 & $94 \pm 7$ & \multicolumn{4}{|c|}{ reference } \\
\hline & $51-100 \%$ & 29 & $75 \pm 32$ & $0.939^{\dagger}$ & $(0.892-0.987)$ & 0.948 & $(0.898-1.001)$ \\
\hline \multirow[t]{2}{*}{ Korean } & $1-50 \%$ & 43 & $92 \pm 10$ & \multicolumn{4}{|c|}{ reference } \\
\hline & $51-100 \%$ & 24 & $74 \pm 35$ & $0.961^{\dagger}$ & $(0.930-0.993)$ & $0.958^{\dagger}$ & $(0.922-0.996)$ \\
\hline \multirow[t]{2}{*}{ English } & $1-50 \%$ & 24 & $94 \pm 8$ & \multicolumn{4}{|c|}{ reference } \\
\hline & $51-100 \%$ & 43 & $81 \pm 28$ & $0.940^{\dagger}$ & $(0.883-1.000)$ & 0.941 & $(0.879-1.008)$ \\
\hline \multirow[t]{2}{*}{ Mathematics } & $1-50 \%$ & 40 & $94 \pm 7$ & \multicolumn{4}{|c|}{ reference } \\
\hline & $51-100 \%$ & 27 & $74 \pm 33$ & $0.940^{\dagger}$ & $(0.896-0.987)$ & 0.950 & $(0.902-1.001)$ \\
\hline \multirow[t]{2}{*}{ Social studies } & $1-50 \%$ & 32 & $94 \pm 9$ & \multicolumn{4}{|c|}{ reference } \\
\hline & $51-100 \%$ & 35 & $79 \pm 30$ & $0.952^{\dagger}$ & $(0.909-0.996)$ & $0.924^{\dagger}$ & $(0.867-0.985)$ \\
\hline \multirow[t]{2}{*}{ Science } & $1-50 \%$ & 30 & $94 \pm 7$ & \multicolumn{4}{|c|}{ reference } \\
\hline & $51-100 \%$ & 37 & $79 \pm 30$ & $0.947^{\dagger}$ & $(0.900-0.996)$ & $0.926^{\dagger}$ & $(0.868-0.988)$ \\
\hline \multirow[t]{2}{*}{ Art and music } & $1-50 \%$ & 41 & $91 \pm 17$ & \multicolumn{4}{|c|}{ reference } \\
\hline & $51-100 \%$ & 26 & $78 \pm 30$ & 0.976 & $(0.952-1.001)$ & 0.981 & $(0.955-1.009)$ \\
\hline \multicolumn{8}{|c|}{ Communications at school } \\
\hline \multirow[t]{2}{*}{ Q1 } & $\mathrm{A} 1-2$ & 37 & $94 \pm 6$ & \multicolumn{4}{|c|}{ reference } \\
\hline & A3-5 & 30 & $75 \pm 32$ & $0.924^{\dagger}$ & $(0.872-0.980)$ & $0.925^{\dagger}$ & $(0.868-0.986)$ \\
\hline \multirow[t]{2}{*}{ Q2 } & $\mathrm{A} 1-2$ & 53 & $93 \pm 8$ & \multicolumn{4}{|c|}{ reference } \\
\hline & A3-5 & 14 & $59 \pm 40$ & $0.929^{\dagger}$ & $(0.885-0.977)$ & $0.937^{\dagger}$ & $(0.888-0.989)$ \\
\hline \multirow[t]{2}{*}{ Q3 } & $\mathrm{A} 1-2$ & 35 & $94 \pm 6$ & \multicolumn{4}{|c|}{ reference } \\
\hline & $A 3-5$ & 32 & $77 \pm 31$ & $0.939^{\dagger}$ & $(0.892-0.990)$ & $0.930^{\dagger}$ & $(0.877-0.987)$ \\
\hline \multirow[t]{2}{*}{ Q4 } & $\mathrm{A} 1-2$ & 59 & $87 \pm 21$ & \multicolumn{4}{|c|}{ reference } \\
\hline & A3 -4 & 8 & $75 \pm 37$ & 0.984 & $(0.960-1.008)$ & $0.881^{\dagger}$ & $(0.786-0.987)$ \\
\hline
\end{tabular}

Good performers were defined as children who scored above average (within the top 50\%) on the academic achievement questionnaires, or among the top 1 and 2 on the questionnaires on communication skills. The rest of the children were defined as children with poor performance. *A multivariate logistic regression model was constructed adjusting for current age, sex, and listening modes. The bi-syllabic WRSs were measured in auditory only conditions, ${ }^{\dagger} p<0.05$. WRS: word recognition score, N: NucleUs, SD: standard deviation, OR: odds ratio, Cl: confidence interval

\section{Discussion}

In this study, most implanted children (61 of 67) attended ordinary classes with normal-hearing peers in a mainstream school. In Korea, students requiring special education are usually placed in mainstream schools rather than in separate special schools and special classes. Previous studies have emphasized the following principal benefits of inclusive education of implanted children: naturalistic access to typical linguistic and behavioral models of hearing peers, and social acceptance by hearing peers $[6,23,24]$. Children with CIs in mainstream schools reported having friends with mostly normal hearing (Q1 in Table 3). This result reflects their social interactions with peers during school life. Thus, the inclusive education of implanted children in mainstream schools appears to provide opportunities for contact and social interactions with normal peers. Based on the responses to the psychosocial development questions (self-esteem and social relations section in Table 3), most implanted children in mainstream schools seemed to have a positive attitude towards self-esteem and confidence.

In a mainstream education setting, half the implanted children scored above average in general academic achievement (Fig. 1A). Consistent with a previous study [13], academic achievement was best in mathematics. However, academic achievement in a second language (English) and social studies were usually poorer than general academic achievement (Fig. 1A). Particularly, our cohort reported difficulty in listening comprehension and pronunciation in English. When interviewed, the children also had difficulty understanding abstract concepts in social studies and science. Children with lower scores on the bi-syllabic identification test were significantly likely to have poor academic performance in social studies and science (Table 4). This may be because these subjects are often taught with complex verbal explanations. Children with $\mathrm{CI}$ have been reported to experience delays in 
concept formation [25]. Therefore, it is necessary to provide these children with various supplementary materials or preteach them the subject-relevant vocabulary so that the new information can be integrated meaningfully into the prior knowledge framework.

Most implanted children had little difficulty in conversing in a quiet background at school or home (Table 3). However, communication at school was considerably more challenging than at home in a noisy background. In a noisy background, $24 \%$ of the implanted children responded having some difficulty communicating at home, while half of the implanted children (48\%) had some difficulty conversing at school. Also, half of the implanted children (45\%) had difficulty in understanding the class. Although children with CIs can perceive speech, they may have difficulty in understanding during group or outdoor activities. Therefore, providing a good listening environment by considering the seating arrangements or using hearing assistive technologies such as personal FM systems for some children with poor speech perception is necessary for improving classroom performance.

This study had several limitations. First, the academic performance outcomes are mostly derived from parents' opinions rather than from scores on validated measures directly testing the children's outcomes. Careful observation of implanted children's classroom performance is required in both national and school-based achievement testing for tracking studies. Second, this study included a heterogeneous group of children in terms of age, implantation age, CI device characteristics, presence or absence of additional disabilities, and the range of received educational supports. This study did not consider the CI device characteristics or educational supports. However, when adjusted for current age, sex, and listening modes, this study demonstrated that speech performance was significantly associated with academic performance. Educating children with CIs in mainstream schools appears to positively impact self-esteem and confidence in social integration in the future. However, 12 of the 67 implanted children attending mainstream schools experienced one or more grade retention episodes. The academic performance of CI children in mainstream schools was mostly satisfactory; however, they scored below average in some subjects. Furthermore, they reported some difficulty in understanding the class content and holding a conversation in a noisy background. Most of these difficulties were reflected by poor speech perception. Therefore, improving the listening environment for implanted children in mainstream schools is necessary.

\section{Supplementary Materials}

The online-only Data Supplement is available with this ar- ticle at https://doi.org/10.7874/jao.2019.00346.

\section{Acknowledgments}

None.

\section{Conflicts of interest}

The authors have no financial conflicts of interest.

\section{Author Contributions}

Conceptualization: Sung Hwa Hong and Il Joon Moon. Data curation: Ji Eun Choi. Formal analysis: Ji Eun Choi. Methodology: Il Joon Moon. Project administration: Sung Hwa Hong. Supervision: Il Joon Moon. Visualization: Ji Eun Choi. Writing — original draft: Ji Eun Choi. Writing — review \& editing: Ji Eun Choi and Il Joon Moon. Approval of final manuscript: All authors.

\section{ORCID iDs}

Ji Eun Choi

Sung Hwa Hong

https://orcid.org/0000-0001-8105-813X

Il Joon Moon

https://orcid.org/0000-0001-6906-8925

https://orcid.org/0000-0002-3613-0734

\section{REFERENCES}

1) Svirsky MA, Robbins AM, Kirk KI, Pisoni DB, Miyamoto RT. Language development in profoundly deaf children with cochlear implants. Psychol Sci 2000;11:153-8.

2) Richter B, Eissele S, Laszig R, Löhle E. Receptive and expressive language skills of 106 children with a minimum of 2 years' experience in hearing with a cochlear implant. Int J Pediatr Otorhinolaryngol 2002;64:111-25.

3) Calmels MN, Saliba I, Wanna G, Cochard N, Fillaux J, Deguine O, et al. Speech perception and speech intelligibility in children after cochlear implantation. Int J Pediatr Otorhinolaryngol 2004;68:347-51.

4) Connor CM, Craig HK, Raudenbush SW, Heavner K, Zwolan TA. The age at which young deaf children receive cochlear implants and their vocabulary and speech-production growth: is there an added value for early implantation? Ear Hear 2006;27:628-44.

5) Nicholas JG, Geers AE. Effects of early auditory experience on the spoken language of deaf children at 3 years of age. Ear Hear 2006; 27:286-98.

6) Xie YH, Potměšil M, Peters B. Children who are deaf or hard of hearing in inclusive educational settings: a literature review on interactions with peers. J Deaf Stud Deaf Educ 2014;19:423-37.

7) Francis HW, Koch ME, Wyatt JR, Niparko JK. Trends in educational placement and cost-benefit considerations in children with cochlear implants. Arch Otolaryngol Head Neck Surg 1999;125:499-505.

8) Punch R, Hyde M. Children with cochlear implants in Australia: educational settings, supports, and outcomes. J Deaf Stud Deaf Educ 2010;15:405-21.

9) Geers A, Brenner C. Background and educational characteristics of prelingually deaf children implanted by five years of age. Ear Hear 2003;24:2S-14S.

10) Wu CM, Liu TC, Liao PJ, Chen CK, Chang BL, Lin BG. Academic achievements and classroom performance in Mandarin-speaking prelingually deafened school children with cochlear implants. Int J Pediatr Otorhinolaryngol 2013;77:1474-80.

11) Motasaddi-Zarandy M, Rezai H, Mahdavi-Arab M, Golestan B. The scholastic achievement of profoundly deaf children with cochlear implants compared to their normal peers. Arch Iran Med 2009;12: 441-7.

12) Damen GW, van den Oever-Goltstein MH, Langereis MC, Chute PM, Mylanus EA. Classroom performance of children with cochlear implants in mainstream education. Ann Otol Rhinol Laryngol 
2006;115:542-52.

13) Mukari SZ, Ling LN, Ghani HA. Educational performance of pediatric cochlear implant recipients in mainstream classes. Int J Pediatr Otorhinolaryngol 2007;71:231-40.

14) Spencer LJ, Gantz BJ, Knutson JF. Outcomes and achievement of students who grew up with access to cochlear implants. Laryngoscope 2004;114:1576-81.

15) Wauters LN, Knoors H. Social integration of deaf children in inclusive settings. J Deaf Stud Deaf Educ 2008;13:21-36.

16) Schorr EA. Early cochlear implant experience and emotional functioning during childhood: Loneliness in middle and late childhood. Volta Review 2006;106:365-79.

17) Punch R, Hyde M. Social participation of children and adolescents with cochlear implants: a qualitative analysis of parent, teacher, and child interviews. J Deaf Stud Deaf Educ 2011;16:474-93.

18) Martin D, Bat-Chava Y, Lalwani A, Waltzman SB. Peer relationships of deaf children with cochlear implants: predictors of peer entry and peer interaction success. J Deaf Stud Deaf Educ 2011;16:10820.
19) Bat-Chava Y, Deignan E. Peer relationships of children with cochlear implants. J Deaf Stud Deaf Educ 2001;6:186-99.

20) Carhart R, Jerger JF. Preferred method for clinical determination of pure-tone thresholds. J Speech Hear Disord 1959;24:330-45.

21) Ling D. Speech development in hearing-impaired children. J Commun Disord 1978;11:119-24.

22) Moon IJ, Kim EY, Chu H, Chung WH, Cho YS, Hong SH. A new measurement tool for speech development based on Ling's stages of speech acquisition in pediatric cochlear implant recipients. Int J Pediatr Otorhinolaryngol 2011;75:495-9.

23) Percy-Smith L, Jensen JH, Cayé-Thomasen P, Thomsen J, Gudman M, Lopez AG. Factors that affect the social well-being of children with cochlear implants. Cochlear Implants Int 2008;9:199-214.

24) van Gent T, Goedhart AW, Hindley PA, Treffers PD. Prevalence and correlates of psychopathology in a sample of deaf adolescents. J Child Psychol Psychiatry 2007;48:950-8.

25) Castellanos I, Kronenberger WG, Beer J, Colson BG, Henning SC, Ditmars A, et al. Concept formation skills in long-term cochlear implant users. J Deaf Stud Deaf Educ 2015;20:27-40. 